\title{
Using symptoms to effectively dose therapeutic exercises for a female with multiple sclerosis after an acute exacerbation: A case report
}

\author{
Alexis Mielke, Rolando Lazaro* and Gail Widener \\ *Correspondence: rlazaro@samuelmerritt.edu

Department of Physical Therapy, Samuel Merritt University, California, USA.

\begin{abstract}
Background: There is limited research on effective physical therapy interventions for a person with multiple sclerosis (MS) directly following an exacerbation of the condition. The purpose of this case report is to describe a short-term physical therapy plan of care (POC) using the patient's symptoms to guide intensity of interventions aimed at improving walking distance, functional mobility, and lower extremity (LE) strength for a patient following an acute MS exacerbation in an inpatient setting.

Case presentation: The patient, a 30-year-old woman with a two-month history of MS, experienced an exacerbation resulting in bilateral LE weakness, inability to ambulate, and increased fatigue. The patient received physical therapy three weeks after the onset of her exacerbation. The primary interventions used throughout the POC were gait training and LE strengthening. Onset of the patient's symptoms of perceived exertion, shortness of breath, numbness and tingling in extremities, pain, dizziness, and onset of blurring vision were used to dose her exercise threshold.

Discussion: The patient was seen for one and a half to two hours per day. She demonstrated increased ambulation distance by 118 feet. She demonstrated increased gait speed, LE strength and decreased perceived fatigue. No adverse effects were noted during her entire episode of care.

Conclusions: This case demonstrates how using a patient's symptoms of MS may be an appropriate method to dose the intensity of interventions to improve endurance with ambulation, LE strength, and functional mobility in a patient after an acute MS exacerbation.
\end{abstract}

Keywords: Multiple sclerosis, fatigue, exercise, exacerbation, physical therapy

\section{Background}

Relapsing remitting multiple sclerosis (MS) comprises approximately $80 \%$ of MS cases and is characterized by an exacerbation of symptoms [1]. An exacerbation is defined in the literature as a patient-reported or objectively observed event that is consistent with an acute inflammatory demyelinating event in the central nervous system (CNS) [2]. This event must occur for at least 24 hours, without the presence of fever or infection. Symptoms of exacerbations vary and commonly include muscle weakness in extremities, fatigue, and difficulty with coordination and balance $[1,3]$.

It is customary to wait two weeks after the attack before starting or resuming physical therapy [4], however there is no evidence supporting this recommendation. No published studies have addressed whether exercise during an exacerbation results in worsening of MS symptoms or any other adverse effects.

The common thread of patient education for people with MS includes instructions to avoid increasing core temperature by internal (exercise) or external (ambient heat) methods, creating fear in this population of over exertion causing exacerbation of their symptoms. This results in an unfortunate limitation of their activity level leading to deconditioning and greater weakness, fatigue, and health risks inherent with deconditioning [5]. No evidence exists that suggests exercise causes detrimental effects in people with MS [6]. Instead, exercise may reduce the risk of cardiovascular disease, mortality, depression, osteoporosis 
Mielke et al. Physical Therapy and Rehabilitation 2016,

and diabetes mellitus, improve quality of life, and reduce the overall disability in a person with MS [5].

Although it is widely accepted that people with MS will benefit from exercise, there is no evidence on the adverse effects of exercise directly following an exacerbation. While studies of people with MS report an improvement with fatigue, aerobic capacity, and ambulation with aerobic and resistance training [7-9], authors of these studies excluded any person who experienced an exacerbation in the previous four to eight weeks. It is therefore uncertain whether people after an acute exacerbation would have the same benefits. In addition, parameters for activity threshold following an exacerbation have not been studied. People with MS can often experience symptoms with onset of exercise that healthy individuals would not, such as blurred vision, tingling, pins and needles sensation, and pain [10]. Therefore, parameters used to determine exercise threshold in healthy individuals could not be applied to this population. The purpose of this case report is to describe a short-term plan of care (POC) using the onset of MS symptoms to guide intensity of interventions aimed at improving walking endurance, lower extremity (LE) strength, and functional mobility after an MS exacerbation.

\section{Case presentation}

The patient, a 30-year-old woman diagnosed with an acute exacerbation of MS, was previously independent with activities of daily living and a stay-at-home mother. Her exercise consisted of walking and playing with her two-year-old daughter. The patient was a highly motivated, young woman who was in the early stages of MS, which were positive indicators for her to be able to develop effective coping strategies to maintain a high quality of life throughout the progression of the disease.

She was diagnosed with MS two months prior after her first exacerbation. During the first episode the patient experienced symptoms of flickering lights in the right eye, general fatigue, dizziness, and shortness of breath. The patient returned to independence with all activities after this incident. Three weeks prior to initial examination the patient experienced a second, more severe, exacerbation resulting in total body muscle weakness, blurred vision, pain, flickering lights in right eye, and problems with ambulation. The patient spent four days in the acute care hospital where she was treated with corticosteroids to decrease inflammation in the central nervous system (CNS). She was discharged to an inpatient rehabilitation facility where she received the physical therapy described in this case report. Other medical history included gastroesophageal reflux disease (GERD) and hyperlipidemia. She took amitriptyline for paresthesias in the extremities, gabapentin for dysesthesias and neuropathic pain, acetaminophen and hydrocodone for pain relief, and pantoprazole for GERD. The patient's chief concern was severe pain in bilateral lower extremities (LEs) with fatigue and weakness of her whole body, her legs being more affected than her arms. She reported increased fatigue with all functional activities. As her fatigue increased, she experienced symptoms of shortness of breath, numbness and tingling in extremities, dizziness, headaches, and blurred vision of her right eye. The patient's primary goal was "to be able to walk again." Written informed consent was obtained from the patient for publication of this case.

On examination, the patient required minimal assistance for bed mobility, maximal assistance of two people for sit to stand, and minimal assistance during ambulation in the parallel bars with bilateral upper extremity (UE) support for eight feet. A full motor control, balance and neurological examination was performed (Table 1). Muscle strength was measured with manual muscle testing (MMT) [11] with adjustments made to the standard positions due to severity of symptoms (Table 2). The LEs were weaker than the UEs. MMT scores in bilateral LEs ranged from 2- to $3+$ out of 5 and bilateral UE scores ranged from $3+$ to 5 out of 5 . The patient demonstrated impaired sensation to light touch of the left UE, the left LE, and the right face.

The static and dynamic sitting balance scores and static standing balance scores were defined by the physical therapy department at the rehabilitation facility. The dynamic standing balance score used were defined by O'Sullivan [12]. Her

Table 1. Sensory and motor function initial examination ${ }^{\mathrm{a}}$.

\begin{tabular}{lll}
\hline Test & Left & Right \\
\hline Light touch sensation UE/LE $^{\mathrm{b}}$ & Impaired & Intact \\
Superficial pain sensation UE/LE & Intact & Intact \\
Proprioception & Intact & Intact \\
Cranial nerve (CN) III, IV, VI & Intact & Intact \\
CN II & Intact & Impaired \\
Deep tendon reflexes & Normal & Normal \\
Passive straight leg raise test & Negative & Negative \\
Selective motor control & Normal & Normal \\
Tone of UE and LE & NT & NT \\
\hline
\end{tabular}

aAs described by Schmidt and O'Sullivan [12] unless otherwise stated.

'The patient's sensation was tested in a random cortical pattern due to the unpredictable sensation loss with MS. NT: Not tested secondary to pain.

Table 2. Manual muscle testing of lower extremities ${ }^{\mathrm{a}}$.

\begin{tabular}{lllll}
\hline Muscle Group & $\begin{array}{l}\text { Left } \\
\text { (Initial) }\end{array}$ & $\begin{array}{l}\text { Left } \\
\text { (Final) }\end{array}$ & $\begin{array}{l}\text { Right } \\
\text { (Initial) }\end{array}$ & $\begin{array}{l}\text { Right } \\
\text { (Final) }\end{array}$ \\
\hline Hip Flexors & $2+$ & $3+$ & $2+$ & $3+$ \\
Hip Abductors & $2-$ & $3+$ & $2-$ & $3+$ \\
Hip Adductors & $2-$ & N/T & $2-$ & N/T \\
Knee Flexors & $2-$ & $3+$ & $2-$ & $3+$ \\
Knee Extensors & $2-$ & 4 & $2-$ & 4 \\
Ankle Dorsiflexors & $3+$ & $3+$ & $3+$ & $3+$ \\
\hline
\end{tabular}

${ }^{a}$ Followed protocol as described by Reese [11]. All scores were out of 5 . Testing performed withhead of bed elevated to 75 degrees on initial examination and in sitting at the edge of maton final examination. 
static and dynamic sitting balance was scored as "good." The patient's static and dynamic standing balance was scored as "poor" due to her inability to stand without maximal assist of two people. Her ambulating balance was "poor" because she required assistance to ambulate.

The Disease Steps scale is a valid and reliable measure of the progression of severity of MS and is an appropriate outcome measure for limited ambulators $[13,14]$. The higher the level, the greater the severity. On examination, she was a level 6 defined as, "Essentially confined to a wheelchair or scooter. They may be able to take a few steps but are unable to ambulate 25 feet, even with bilateral support." The motor component of the Functional Independent Measure (M-FIM) was used to measure the patient's motor disability in categories of self-care, bowel and bladder management, stairs, transfers, and locomotion [15]. The higher the score indicates more independence. The patient's M-FIM score was 45 out of 91.

Self-report measures were used to understand the patient's perspective of fatigue, depression, and the impact of MS on her life. The Multiple Sclerosis Impact Scale (MSIS-29) is a valid and reliable measure of the impact of MS on quality of life including the patient's perception of tolerance for exercise, social activities, and ability to lead a normal lifestyle $[16,17]$. The higher the score indicates greater disability; the patient in our study scored 115 out of 145 . The Modified Fatigue Impact Scale-5-item (MFIS-5) is used to quantify a patient's fatigue level [18]. The MFIS-5 consists of items from all three subscales of the MFIS standard 21-item version: physical, cognitive, and psychosocial [19]. It is recommended for use when time is limited, however has not been validated for patients with MS [18]. The higher score indicates greater fatigue; the patient scored 19 out of 20.

Several physical therapy interventions were performed. Endurance training and progressive resistance exercise were used as primary interventions to increase ambulation capacity and muscle strength for improvement of functional mobility. During each session the patient's MS symptoms of general fatigue as measured by perceived exertion, LE pain, numbness, tingling, shortness of breath, or blurring vision were used as the patient's threshold for exercise. When the patient had onset of symptoms, she was encouraged to rest until they subsided and continue as tolerated. Another overall focus to the following interventions was to create a balanced exercise program to encourage good exercise habits in the early stages of her disease.

Gait training was used to increase the patient's endurance by improving body mechanics throughout the gait cycle to conserve energy and slow the onset of MS symptoms during ambulation. It was predicted that she would reach her aerobic threshold at the point of symptom onset, increasing her oxygen uptake and thus increasing her ability to tolerate greater workloads over time [5]. Gait training was initiated in parallel bars and eventually progressed to use of a front-wheeled walker (FWW). Once this goal was attained, the 2-minute walk test
(2MWT) was chosen to objectively measure her gait distance. The 2MWT is a valid measure of walking capacity for patients with MS; however, it has not been tested in patients with an acute exacerbation or in individuals with severe MS $[\mathbf{2 0 , 2 1}$. The patient's gait speed was 0.038 meters per second, indicating she was at risk for falls [22]. Gait training was performed two to three minutes at a time for a total of 30 minutes per session, one to two times per day for 10 days. The patient's heart rate (HR) and oxygen saturation were measured before and after ambulation activities to assess changes in aerobic capacity. The patient required rest breaks, approximately three to five minutes each time, for symptoms to subside enough to resume ambulation.

Progressive resistance training in patients with MS has been effective in augmenting the magnitude of efferent motor output of spinal motor neurons and inducing both muscle hypertrophy and neural adaptations [23]. Active-assisted exercises such as heel slides, bridges with minimal assistance, mini squats in the parallel bars, and anterior and lateral stepsups with minimal to moderate assistance were implemented initially. In the second week the patient progressed to the suggested guidelines to improve muscle strength and functional capacity in people with MS, namely two to four sets of eight to 15 repetitions, two to three sessions per week for three to 20 weeks [23]. Resistance exercises included bridges, pelvic stability in hook-lying, step-ups, and side-lying clams. Her dosage ranged from two sets of 10 to 15 repetitions. The patient was instructed to perform repetitions until the onset of MS symptoms (specifically pain, numbness or tingling), or until proper form was compromised, whichever came first.

\section{Discussion}

The patient completed a total of 20 sessions over two weeks. The patient improved in all outcome measures (Table 3). The patient's gait distance improved 11 times her original distance. At initial examination her 2MWT was 15 feet with bilateral UE support in the parallel bars. The patient significantly improved her 2MWT score by 118 feet, greater than the minimum detectable change (MDC) of 63 feet [21]. On discharge she ambulated 172 feet with the FWW and supervision.

Table 3. Outcomes.

\begin{tabular}{llll}
\hline Outcome measures & Initial & Final & Change \\
\hline 2MWT $^{\mathrm{a}}$ & $15 \mathrm{ft}$. & $133 \mathrm{ft}$. & $+118 \mathrm{ft}$. \\
Gait Speed & $0.038 \mathrm{~m} / \mathrm{s}$ & $0.16 \mathrm{~m} / \mathrm{s}$ & $+0.1562 \mathrm{~m} / \mathrm{s}$ \\
Disease Steps & Level 6 & Level 5 & -1 level \\
M-FIM $^{\mathrm{b}}$ & $45 / 91$ & $79 / 91$ & +34 points \\
MSIS-29 $^{\mathrm{c}}$ & $115 / 145$ & $89 / 145$ & -26 points \\
MFIS-5 $^{\mathrm{d}}$ & $19 / 20$ & $9 / 20$ & -10 points \\
\hline
\end{tabular}

a2-minute walk test

bmotor component of the Functional Independent Measure

${ }^{c}$ Multiple Sclerosis Impact Scale

${ }^{\mathrm{d}}$ Modified Fatigue Impact Scale-5-item 
Mielke et al. Physical Therapy and Rehabilitation 2016,

http://www.hoajonline.com/journals/pdf/2055-2386-3-2.pdf

doi: $10.7243 / 2055-2386-3-2$

The patient displayed improved aerobic capacity with a delay of onset of symptoms during ambulation. Throughout the course of treatment the patient was able to tolerate longer distances using less effort with decreased or an equal percent of her maximum HR. On day six the patient ambulated 40 feet with a FWW at $60 \%$ of her maximum HR and on day nine she ambulated 133 feet at $58 \%$ of her maximum HR.

The patient demonstrated improved gross strength of bilateral LEs with MMT. Her results from initial examination ranged from 2- to $3+$ out of 5 and on final examination she scored grossly $3+$ to 4 out of 5 (Table 2). During progressive resistance exercises, the patient was able to perform more repetitions with decreased assistance. She performed five mini squats with bilateral UE support with minimal assistance on initial examination and ten repetitions with bilateral UE support independently on final examination. By final examination, she performed an average of four and a half times as many double leg bridges and double leg squats as she did on initial examination.

The patient's level of disability improved on the Disease Steps outcome measure from level 6 to level 5, defined as "Patient requires bilateral support to walk 25 feet (with a walker). They may use a scooter for greater distances. The pattern of disease is relapsing-remitting or progressive [13]." The patient was more independent with functional activities on the M-FIM as indicated by an increase of 34 points due to her improvements in bathing, lower body dressing, toileting, distance walked, and stair ambulation. The MDC of the FIM Motor Subscale has not been studied in people with MS. The patient reported decreased fatigue on the MFIS- 5 with a decrease in score from 19 to 9 . The MFIS-5 item does not have MDC values and therefore cannot be detected, however the patient had a trend of improvement of 50 percent.

The patient had an overall decrease in disability as recorded by the MSIS-29. She reported improved confidence and ability to sleep as well as less worry, anxiety, and mental fatigue. The MDC for the MSIS-29 is 8 points to be clinically significant [25]. The patient's score in this case report improved by 26 points.

Most importantly she regained independence with functional mobility, which allowed her to return home. By final examination the patient could stand up from her chair with modified independence and a FWW, she could transfer from a bed to the floor to play with her two-year-old daughter, and she could walk up a flight of stairs with bilateral UE support on the handrails to get to her bedroom.

This case demonstrates how using the patient's symptoms of MS was an appropriate method of dosing intensity of interventions to improve endurance, LE strength, fatigue, and functional mobility after an acute MS exacerbation. Although there are no studies observing the impact of exercise within three weeks of an exacerbation, the findings of this case report are consistent with exercise studies in people with MS $[\mathbf{9 , 2 4 ]}$.

The results, however impressive, cannot demonstrate a cause and effect relationship to this POC and cannot be generalized to the population of patients with an acute MS exacerbation. One of the biggest confounding factors for measuring the effectiveness of physical therapy interventions for a patient after an MS exacerbation is spontaneous recovery. There is high variability among patients with MS and the amount of time it takes for them to regain function close to their baseline, with some never returning [6]. It is difficult to predict how much improvement the patient made was due to intensive therapy versus the nature of the disease. Further research is needed for the effect of exercise, particularly endurance and strength training, in patients with MS acutely following an exacerbation. It has been hypothesized that exercise may have an effect on the severity of MS and possibly reduce the number of MS exacerbations, however, it has not yet been sufficiently examined [26].

\section{Conclusions}

Exercise is important for persons with MS to maintain independence and prevent deconditioning associated with lack of activity. The approach in this case report uses a simple parameter such as their symptoms to guide the intensity and duration of activity after an acute MS exacerbation. Due to the lack of adverse effects of provoking symptoms people with MS can exercise safely and effectively, thus decreasing their risk of deconditioning. A study reported that residual deficits that persist for three months post exacerbation usually do not resolve [27]. Therefore, it is important the patient learns good exercise habits after an exacerbation to return to prior level of function as quickly as possible. By teaching patients how to be aware of their MS symptoms we are giving them more autonomy over their rehabilitation after an exacerbation. If patients can effectively monitor their exercise threshold by using appearance and disappearance of symptoms as a measuring tool, they may be more comfortable performing aerobic and resistance exercises to decrease the risk of long-term disability.

\section{Competing interests}

The authors declare that they have no competing interests.

Authors' contributions

\begin{tabular}{|l|c|c|c|}
\hline Authors' contributions & AM & RL & GW \\
\hline Research concept and design & $\checkmark$ & -- & -- \\
\hline Collection and/or assembly of data & $\checkmark$ & -- & -- \\
\hline Data analysis and interpretation & $\checkmark$ & $\checkmark$ & -- \\
\hline Writing the article & $\checkmark$ & $\checkmark$ & -- \\
\hline Critical revision of the article & $\checkmark$ & $\checkmark$ & $\checkmark$ \\
\hline Final approval of article & $\checkmark$ & $\checkmark$ & -- \\
\hline Statistical analysis & $\checkmark$ & -- & -- \\
\hline
\end{tabular}

\section{Acknowledgement}

Tha authors thank Lucia Pacciotti for her valuable feedback during the development of the manuscript.

\section{Publication history}

Editor: John Alderink, Grand Valley State University, USA. Received: 21-Dec-2015 Final Revised: 09-Feb-2016 Accepted: 10-Feb-2016 Published: 19-Feb-2016 
Mielke et al. Physical Therapy and Rehabilitation 2016,

\section{References}

1. Noseworthy JH, Lucchinetti C, Rodriguez M and Weinshenker BG. Multiple sclerosis. N Engl J Med. 2000; 343:938-952. | Article

2. Polman $\mathrm{CH}$, Reingold $\mathrm{SC}$, Banwell $\mathrm{B}$, Clanet $\mathrm{M}$, Cohen JA, Filippi $\mathrm{M}$, Fujihara K, Havrdova E, Hutchinson M, Kappos L, Lublin FD, Montalban X, O'Connor P, Sandberg-Wollheim M, Thompson AJ, Waubant E, Weinshenker B and Wolinsky JS. Diagnostic criteria for multiple sclerosis: 2010 revisions to the McDonald criteria. Ann Neurol. 2011; 69:292-302. | Article | PubMed Abstract | PubMed FullText

3. National institute of neurological disorders and stroke multiple sclerosis information page. National Institutes of Health: National Institute of Neurological Disorders and Stroke website. | Website

4. Provance PG. Physical Therapy in Multiple Sclerosis Rehabilitation. New York, NY: National Multiple Sclerosis Society. Clinical Bulletin: Information for Health Professionals. 2011. I Pdf

5. Mostert $\mathrm{S}$ and Kesselring J. Effects of a short-term exercise training program on aerobic fitness, fatigue, health perception and activity level of subjects with multiple sclerosis. Mult Scler. 2002; 8:161-8. | Article | PubMed

6. Brown TR and Kraft GH. Exercise and rehabilitation for individuals with multiple sclerosis. Phys Med Rehabil Clin N Am. 2005; 16:513-55. | Article | PubMed

7. Dodd KJ, Taylor NF, Shields N, Prasad D, McDonald E and Gillon A. Progressive resistance training did not improve walking but can improve muscle performance, quality of life and fatigue in adults with multiple sclerosis: a randomized controlled trial. Mult Scler. 2011; 17:1362-74. | Article | PubMed

8. Dalgas U, Stenager E, Jakobsen J, Petersen T, Hansen HJ, Knudsen C, Overgaard $\mathrm{K}$ and Ingemann-Hansen T. Resistance training improves muscle strength and functional capacity in multiple sclerosis. Neurology. 2009; 73:1478-84. | Article | PubMed

9. Bjarnadottir $\mathrm{OH}$, Konradsdottir $\mathrm{AD}$, Reynisdottir $\mathrm{K}$ and Olafsson $\mathrm{E}$. Multiple sclerosis and brief moderate exercise. A randomised study. Mult Scler. 2007; 13:776-82. | Article | PubMed

10. Smith RM, Adeney-Steel M, Fulcher G and Longley WA. Symptom change with exercise is a temporary phenomenon for people with multiple sclerosis. Arch Phys Med Rehabil. 2006; 87:723-7. | Article | PubMed

11. Reese NB. Muscle and Sensory Testing. 3rd edition. St. Louis, MO: Elsevier. 2012. | Book

12. Schmitz TJ and O'Sullivan S. Examination of Coordination and Balance. In: O'Sullivan SB, Schmitz TJ, Fulk GD, eds. Physical Rehabilitation. $6^{\text {th }}$ ed. Philadelphia, PA: F.A. Davis Company. 2014; 222. | Book

13. Hohol MJ, Orav EJ and Weiner HL. Disease steps in multiple sclerosis: a simple approach to evaluate disease progression. Neurology. 1995 45:251-5. | Article | PubMed

14. Learmonth YC, Motl RW, Sandroff BM, Pula JH and Cadavid D. Validation of patient determined disease steps (PDDS) scale scores in persons with multiple sclerosis. BMC Neurol. 2013; 13:37. | Article | PubMed Abstract I PubMed FullText

15. Hobart JC, Lamping DL, Freeman JA, Langdon DW, McLellan DL, Greenwood RJ and Thompson AJ. Evidence-based measurement: which disability scale for neurologic rehabilitation? Neurology. 2001; 57:63944. | Article | PubMed

16. Costelloe L, O'Rourke K, Kearney H, McGuigan C, Gribbin L, Duggan M, Daly L, Tubridy N and Hutchinson M. The patient knows best: significant change in the physical component of the Multiple Sclerosis Impact Scale (MSIS-29 physical). J Neurol Neurosurg Psychiatry. 2007; 78:841-4. | Article | PubMed Abstract | PubMed FullText

17. Riazi A, Hobart JC, Lamping DL, Fitzpatrick R and Thompson AJ. Multiple Sclerosis Impact Scale (MSIS-29): reliability and validity in hospital based samples. J Neurol Neurosurg Psychiatry. 2002; 73:701-4. | Article | PubMed Abstract | PubMed FullText

18. Ritvo P, Fischer JS, Miller DM, Andrews H, Paty DW and LaRocca NG. Multiple Sclerosis Quality of Life Inventory: A User's Manual. New York: NY: The Consortium of Multiple Sclerosis Centers Health
Services Research Committee; 1997.National Multiple Sclerosis Society publication. 1997. I Pdf

19. Paul L, Coote S, Crosbie J, Dixon D, Hale L, Holloway E, McCrone P, Miller L, Saxton J, Sincock C and White L. Core outcome measures for exercise studies in people with multiple sclerosis: recommendations from a multidisciplinary consensus meeting. Mult Scler. 2014; 20:1641-50. | Article I PubMed

20. Gijbels D, Dalgas U, Romberg A, de Groot V, Bethoux F, Vaney C, Gebara B, Medina CS, Maamagi H, Rasova K, de Noordhout BM, Knuts K and Feys $\mathrm{P}$. Which walking capacity tests to use in multiple sclerosis? A multicentre study providing the basis for a core set. Mult Scler. 2012; 18:364-71. | Article | PubMed

21. Gijbels D, Eijnde BO and Feys P. Comparison of the 2- and 6-minute walk test in multiple sclerosis. Mult Scler. 2011; 17:1269-72. | Article | PubMed

22. Fritz S and Lusardi M. White paper: "walking speed: the sixth vital sign". J Geriatr Phys Ther. 2009; 32:46-9. | Article | PubMed

23. Kjolhede $T$, Vissing $K$ and Dalgas U. Multiple sclerosis and progressive resistance training: a systematic review. Mult Scler. 2012; 18:1215-28. | Article I PubMed

24. Dettmers C, Sulzmann M, Ruchay-Plossl A, Gutler R and Vieten M. Endurance exercise improves walking distance in MS patients with fatigue. Acta Neurol Scand. 2009; 120:251-7. | Article | PubMed

25. Sutherland $G$ and Andersen MB. Exercise and multiple sclerosis: physiological, psychological, and quality of life issues. J Sports Med Phys Fitness. 2001; 41:421-32. | Article | PubMed

26. Jelinek GA and Hassed CS. Managing multiple sclerosis in primary care: are we forgetting something? Qual Prim Care. 2009; 17:55-61. | Article I PubMed

27. Lublin FD, Baier M and Cutter G. Effect of relapses on development of residual deficit in multiple sclerosis. Neurology. 2003; 61:1528-32. | Article | PubMed

28. Chui K and Schmitz TJ. Examination of Sensory Function. In: O'Sullivan SB, Schmitz TJ, Fulk GD, eds. Physical Rehabilitation. $\mathbf{6}^{\text {th }}$ ed. Philadelphia, PA: F.A. Davis Company. 2014; 105-184.

\section{Citation:}

Mielke A, Lazaro R and Widener G. Using symptoms to effectively dose therapeutic exercises for a female with multiple sclerosis after an acute exacerbation: A case report. Phys Ther Rehabil. 2016; 3:2. http://dx.doi.org/10.7243/2055-2386-3-2 